\title{
SLEEP DISTURBANCE AND SLEEP HABITS IN CHILDREN WITH CHILDHOOD AUTISM IN COMPARISON TO NORMALLY DEVELOPING CHILDREN
}

\author{
Dr Apeksha Hewageegana \\ Lady Ridgeway Hospital for Children, Colombo, Sri Lanka
}

\section{BACKGROUND}

Childhood autism is a neurodevelopmental disorder with a current prevalence of one in sixty eight children. Sleep problems are an important co morbidity in these children and are one of the commonest complaints across the globe. They occur secondary to complex interactions between biological, environmental and family factors. Sleep issues not only affect the health and wellbeing of the child but also the whole family. Sleep problems also known to exacerbate autism symptoms leading to poor engagement with intervention programs. However, extent of the sleep problems, their effect and contributing factors are largely unknown in the local context.

\section{AIMS}

The study aimed to add knowledge to a relatively understudied area by characterising sleep problems in Autism in comparison to normally developing children. It also aimed to examine the sociodemographic characteristics and associated emotional and behavioural characteristics.

\section{METHOD}

This was a hospital based cross sectional comparative study, carried out in Lady Ridgeway Hospital for children, Colombo. Initially, a consecutive sample of 150 subjects for each group was selected with an overall response rate of $82.3 \%$. The response rate between two groups was not significantly different. All children were between two and half years to five years of age with a mean age of 3.7 years for each group. Majority of the sample was male (58.5\%). Autism group had 126 subjects whereas normally developing group had 121 subjects. Both groups completed Child Sleep Habit Questionnaire (CSHQ) and a general questionnaire on basic demographic and medical history.

\section{RESULTS}

Based on parent reported $\mathrm{CSHQ}$, all the children with Childhood autism had a sleep problem (CSHQ >40) while $18.2 \%$ of normally developing children had a sleep problem $(\mathrm{P}<0.001)$. All the subscales except for the sleep disordered breathing subscale were higher for children with autism. Children in the autism group had a significantly later bed time, early wake up time, shorter nap and total duration of sleep $(P<0.001)$. There was an association between CSHQ score and activity level independent of autism status $(P=0.016)$. However, there was no association between CSHQ score and level of frustration, temper tantrums or sensory issues.

\section{CONCLUSION}

The findings of the current study are in keeping with the previous studies. Despite some methodological limitations, this study highlights the high prevalence and diversity of sleep issues in autism group in comparison to normally developing group. The high prevalence rate of sleep problems in autism cohort emphasize the importance of increasing awareness of health practitioners on detecting sleep problems and actively screening for sleep issues in this group. Further studies needed to replicate these findings, explore associated aetiological factors and to plan intervention programs.

\section{Number of normal and disordered sleep (CSHQ $>40)$ subjects within Autism (AUT) and Normal (NOR) groups.}

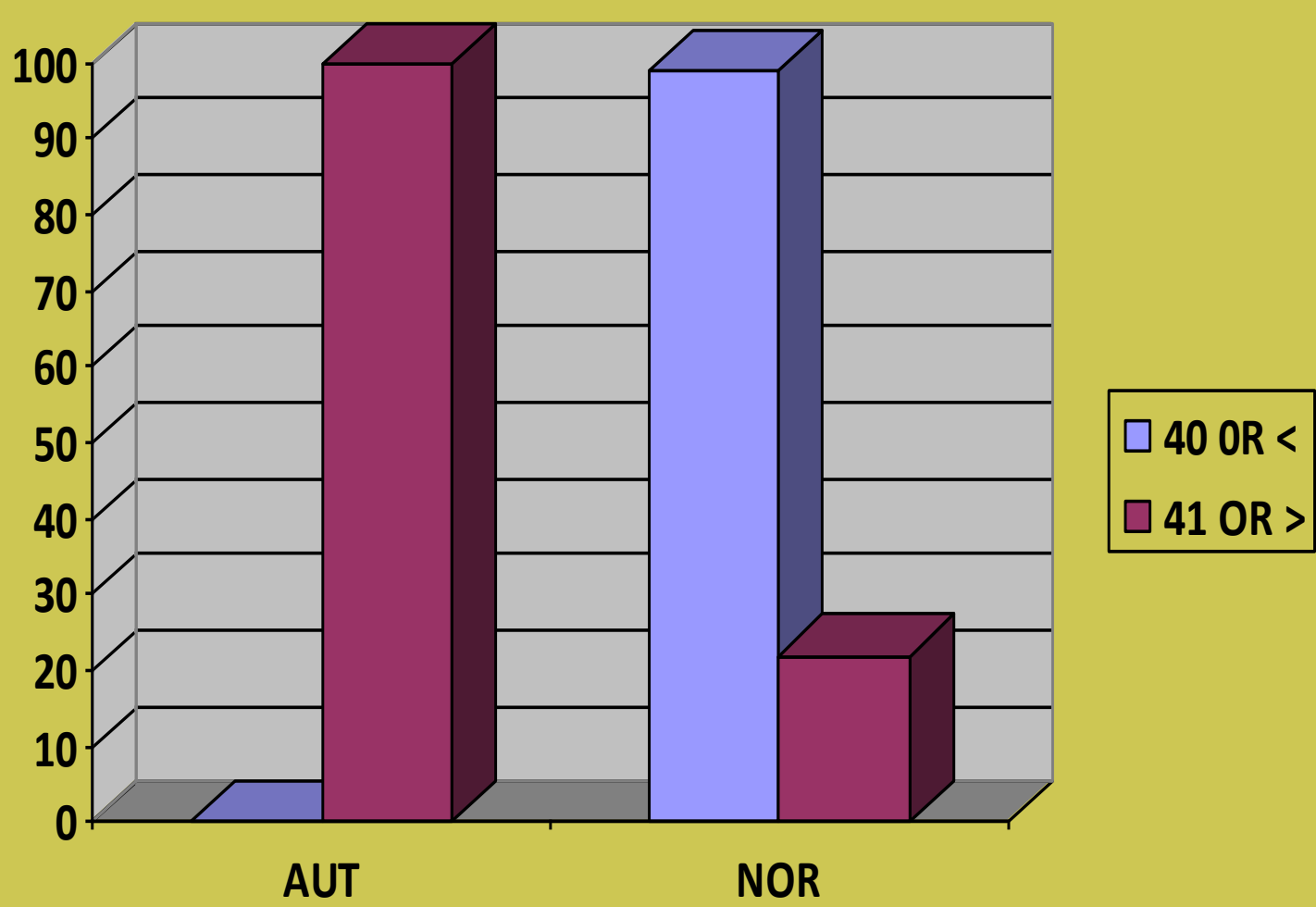

References:

1. ANDERS, T., IOSIF, A. M., SCHWICHTENBERG, A. J., TANG, K. \& GOODLIN-JONES, B. 2012. Sleep and daytime functioning: a shortterm longitudinal study of three preschool-age comparison groups. American Journal on Intellectual \& Developmental Disabilities, 117, 27590.

2. GOODLIN-JONES, B., SCHWICHTENBERG, A. J., IOSIF, A. M., TANG, K., LIU, J. \& ANDERS, T. F. 2009a. Six-month persistence of sleep problems in young children with autism, developmental delay, and typical development. Journal of the American Academy of Child \& Adolescent Psychiatry, 48, 847-54.

3 HIRATA, I., MOHRI, I., KATO-NISHIMURA, K., TACHIBANA, M., KUWADA, A., KAGITANI-SHIMONO, K., OHNO, Y., OZONO, K. \& TANIIKE, M. 2016. Sleep problems are more frequent and associated with problematic behaviors in preschoolers with autism spectrum disorder. Research in Developmental Disabilities, 49-50, 86-99

4. WANG, G., LIU, Z., XU, G., JIANG, F., LU, N., BAYLOR, A. \& OWENS, J. 2016. Sleep Disturbances and Associated Factors in Chinese Children with Autism Spectrum Disorder: A Retrospective and Cross-Sectional Study. Child Psychiatry \& Human Development, 47, $248-58$. 